generates mass mobilisation, street plays and rallies help in effectively reaching the masses.

Conclusions Adopting a multipronged approach works better in building safety culture and creating positive and sustainable change.

\section{EMERGING SAFETY CHALLENGES OF MOTORCYCLES ON BANGLADESH ROADS}

${ }^{1}$ Md Mazharul Hoque, ${ }^{2}$ SM Rahat Rashedi, ${ }^{2}$ Md. Messel Chowdhury, ${ }^{3}$ AKM Fazlur Rahman. ${ }^{1}$ Dean, Faculty of Civil Engineering, and Professor, Department of Civil Engineering, Bangladesh University of Engineering and Technology (BUET), Bangladesh; ${ }^{2}$ Department of Civil Engineering, Bangladesh University of Engineering and Technology (BUET), Bangladesh; ${ }^{3}$ Centre for Injury Prevention and Research, Bangladesh (CIPRB), Bangladesh

\subsection{6/injuryprev-2016-042156.852}

Background Motorcycles are becoming an increasingly popular mode of travel in Bangladesh. There are around 1.3 million registered motorcycles in Bangladesh, representing nearly 55\% of total registered motor vehicles. Motorcycles are increasing at an astonishing rate, around 95\% during 2009-2015 with fleet growing at a faster rate than other vehicles. Motorcycle crashes are a growing problem resulting from massive increase of motorcycles. Methods To assess the risk factors of motorised two wheelers in Bangladesh, police reported crash data were analysed and International Road Assessment Program (iRAP) methodologies were applied in assessing road environment hazards associated with motorcyclists together with field observation of motorcycle travel behaviour.

Results Motorcycle crashes are claiming over 200 deaths annually and nearly $70 \%$ occurred in rural areas, mostly attributable to effects of speeding. Predominant crash types are head-on, hitpedestrian and rear-end, which together account for nearly $86 \%$. Recent iRAP assessment revealed that national highways are mostly 2-star or less for motorcyclists indicating a relatively high level of risks of deaths and injuries. Major risk factors are mostly related to road infrastructure and environmental deficiencies and unsatisfactory driver behaviour and law enforcement.

Conclusions Sustained and accelerated reduction in road fatalities involving pedestrians, bicyclists and motorcyclists is clearly a priority, particularly for achieving the target of $50 \%$ reduction of deaths by 2020 in Bangladesh. Road fatalities involving motorcycles are unacceptably high. Addressing the safety of motorcycles and the riders is therefore an enormous challenge to transport engineering professionals. It is urgent to conduct in depth research and to develop pragmatic strategies and actions with particular emphasis for wider application of road engineering and environment measures for preventing motorcycle crashes and injuries.

\section{UNDERSTANDING ROAD TRAFFIC INJURIES AND PREVENTION MEASURES FOR CHILDREN IN RURAL BANGLADESH: A QUALITATIVE STUDY OF COMMUNITY MEMBERS' VIEWS}

${ }^{1}$ Baset Md, ${ }^{1}$ Kamran UI, ${ }^{2}$ Towner Elizabeth, ${ }^{1}$ Noor Tajkera, ${ }^{1}$ Rahman Aminur, ${ }^{1}$ Islam Munia, ${ }^{1}$ Rahman AKM Fazlur. ${ }^{1}$ Centre for Injury Prevention and Research, Bangladesh (CIPRB); ${ }^{2}$ University of the West of England

\subsection{6/injuryprev-2016-042156.853}

Introduction Road traffic injury (RTI) was the second leading cause of injury mortality and fourth leading of injury morbidity in Bangladesh. For both mortality and morbidity most the vulnerable age group was 5-9 years.

Objectives To gain an in-depth understanding of people's perception of causes and their concepts of prevention of childhood RTIs in rural Bangladesh.

Method Focus Group Discussions (FGDs) were conducted with 7 groups: mothers and fathers of children aged 5-12 years; adolescents; students and non school going children aged 6-12 years, teachers and local leaders. Out of 79 participants 40 were female. The study was conducted in Raiganj rural community in Bangladesh.

Results Most respondents considered that children, aged 5-10 years are at risk of road traffic injuries in rural community, with school going boys being particularly vulnerable. Most of the RTIs were reported to occur on school journey particularly returning home. Key sources of risk identified by participants included: risk taking behaviour, poor supervision, lack of road skills, untrained drivers, unauthorised vehicles, and poorly implemented traffic law. Preventive interventions suggested included supervision, training in road skills, law enforcement by government, increase awareness in the community, and improvement of the road infrastructure.

Conclusions Community people could identify the causes of childhood RTIs and suggest ways of preventing them; but knowledge is not translated into preventative actions. Appropriate community based intervention programmes need to be multi-facet and include practical road safety education for children.

\section{CREATING A MODEL - SAFER SCHOOL ZONE PROJECT}

Madhavi Gunandekar. Safe Kids Foundation, India.

\subsection{6/injuryprev-2016-042156.854}

Background In the mega city like Mumbai, there is need to do a scalable, sustainable and cost effective projects in communities to address road safety is a must. Model school zone project is a part of Walk This Way, pedestrian safety program that was implemented at St. Joseph High School Mumbai, to create safer environment for 2,200 children. Evaluating the school zone and implementing interventions was primary goal of this project.

Method The project was carried out in 3 phases.

Phase I- Gathering statistics and information on accidents from various sources like hospitals, police, traffic \& transport department. 46 stakeholders like road safety experts, engineers, policy makers, parents, teachers, community members, reearch agencies and 178 students were involved in the project. The tools used were school zone assessment, parents' survey, walkability checklist for students, photovoice- children's perspective on road safety, where 10 children were involved, students knowledge and awareness assessment study was also conducted.

Phase II- Interventions - zebra crossing was painted near the school, signanges like school ahead were installed, usage of different school gates, widening of footpaths, fencing the footpath near the school.

Phase III- The reaserch was repeated to study the impact after the interventions. Conducted the post intervention assessment. Interpreted assessment findings.

Results Permanent road infrastructure modifications were carried out. School authorities made modifications in the premises and survey showed behavioural changes amongst children and parents. All worked togther as a cohesive team and showed results. 
Conclusions This pilot study served as model to other schools, governments and organisations working to improve road safety. The project identified areas at risk, brought in behavioural changes, thus effectivenes of the interventions. This project can be effective and adapted for benefit of children globally.

\section{PEDESTRIANS AT HIGHEST RISK IN PAKISTAN}

${ }^{1}$ Muhammed Navid Tahir, ${ }^{2}$ Ali Hammad Akbar, 'Ahsan Kayani, 'Saif Al Ramadhani, ${ }^{1}$ Narelle Haworth, ${ }^{1}$ Mark King, ${ }^{3}$ Rizwan Naseer. 'Queensland University of Technology (QUT), Centre for Accident Research and Road Safety - Queensland (CARRS-Q), Australia; ${ }^{2}$ University of Engineering and Technology, KICS Lahore, Pakistan; ${ }^{3}$ Punjab Emergency Service (Rescue 1122), Lahore, Pakistan

\subsection{6/injuryprev-2016-042156.855}

Background Road crashes and injuries constitute a significant public health issue in Pakistan. Growing urbanisation and motorization trends, traffic violations, encroachments and lack of road safety awareness have placed pedestrians at highest risk in Pakistan. A recent study found that pedestrians constituted 53\% of the reported fatalities in Islamabad, Pakistan during 2008 to 2010. Similarly, Road Traffic Injury Research and Prevention Centre recorded 1,130 road fatalities in Karachi during 2013, wherein 379 (33.5\%) were pedestrians. The current research would be the first large scale study in the country that presents existing pedestrians safety scenario in Pakistan.

Methods Retrospective analysis of Rescue 1122 (an emergency service in Pakistan) crash data for last two years period (July 2013- June 2015) was conducted. Data were collected from 37 major cities of Province Punjab.

Results Rescue 1122 attended 407,628 road crashes across Punjab during the study period, wherein 76,737 pedestrians were injured. Of the total 5,317 fatalities, about 30\% $(n=1,577)$ were pedestrians, and $80 \%$ of them were males. Maximum pedestrian injuries 19,916 (26\%) were reported in Lahore, followed by 12,285 (16\%) in Faisalabad and 4,876 (6\%) in Gujranwala. Motorcycles (59\%), trucks (10\%) and cars $(9 \%)$ were the major colliding vehicles with pedestrians. Whilst, speeding (42\%), careless driving (32\%) and wrong turn (12\%) were the major crash contributing factors.

Conclusions Pedestrians are at highest risk in Pakistan. Speeding, careless driving, disregard of right of way, encroachments and lack of road safety awareness amongst all road users are the major factors behind increasing road crashes and pedestrians' vulnerability in Pakistan. Road crashes are not being dealt as a significant issue in Pakistan. Sustainable efforts on the part of government, transport organisations, law enforcers, community and media are required. School road safety education is also vital in this view.

\section{COMPARATIVE ANALYSIS OF ROAD ACCIDENTS BY GENDER IN EUROPE}

${ }^{1}$ Alexandra Laiou, ${ }^{1}$ Katerina Folla, ${ }^{1}$ George Yannis, ${ }^{2}$ Robert Bauer, ${ }^{2}$ Klaus Machata, ${ }^{2}$ Christian Brandstaetter, ${ }^{3}$ Pete Thomas, ${ }^{3}$ Alan Kirk. ${ }^{1}$ National Technical University of Athens (NTUA), Greece; ${ }^{2}$ Austrian Road Safety Board (KFV), Austria; ${ }^{3}$ Loughborough University, UK

10.1136/injuryprev-2016-042156.856

In 2013, 26.090 people were killed in road accidents throughout the EU, approximately 6.200 females and 19.800 males. Females account for $51 \%$ of the total EU population, but only $24 \%$ of all road fatalities.

The objective of this research is the analysis of basic road safety parameters related to road users' gender in the EU countries, by the use of the EU CARE database with disaggregated data on road accidents and of other data sources such as Eurostat. Time-series data on road accident fatalities by gender from 28 EU countries over a period of 10 years (2004-2013) are correlated with basic safety parameters, such as age, road user type and transport mode. Data from the EU Injury Database are also used to identify injury patterns and improve the assessment of injury severity and additional insight into accident causation for road users by gender is offered through the use of in-depth accident data from the EC SafetyNet project Accident Causation System (SNACS).

In all EU countries, road fatalities decreased between 2004 and 2013 for both females and males. Besides the trends of that period, the proportion of male road fatalities did not change significantly. Amongst EU countries a slight tendency for male proportions to be higher in south is noted. Additionally, the ratio between male and female fatalities increases with age, reaches a peak between the ages of 30-44 and then falls, which reflects a specific gender development in the travel behaviour of men and women in Europe. As regards the road user type, the proportion of passengers' or pedestrians' fatalities is higher for females than the males, while the opposite is true for drivers.

The results of the analysis allow for an overall assessment of the gender-differentiated safety level in the European road network, providing thus useful support to decision makers working for the improvement of safety in the European road network.

\section{CHARACTERISTICS OF ROAD ACCIDENTS WITH YOUNGSTERS IN EUROPE}

Katerina Folla, George Yannis, Alexandra Laiou. National Technical University of Athens, Greece

10.1136/injuryprev-2016-042156.857

Background Youngsters, defined as those who are between 15 and 17 years old, comprise a road user group that exhibits high risk rates due to different causes from other age groups. This age corresponds to the learning of autonomy and more particularly of access to different means of transport. In 2013, around 630 persons aged 15-17 years old were killed in road accidents in the EU, constituting almost $2,5 \%$ of all road accident fatalities for that year.

Methods The objective of this research is the analysis of basic road safety parameters related to young people aged 15-17 years old in the EU countries, by the use of the EU CARE database with disaggregated data on road accidents and of other data sources such as Eurostat. Time-series data on road accidents involving youngsters from $28 \mathrm{EU}$ countries over a period of 10 years (2004-2013) are correlated with basic safety parameters, such as gender, road user type, transport mode, road type, seasonality and day of the week. Data from the EU Injury Database are also used to identify injury patterns and improve the assessment of injury severity.

Results At this age, youngsters are beginning to gain access to driving motorised vehicles and especially motorised two-wheelers. As a result, motorised two-wheelers' share is much higher for 15-17 year olds than for the other age groups. Moreover, girls killed in road accidents were more likely to be killed as 